\title{
ĐÁNH GIÁ KẾT QUẢ SAU PHÃU THUẠTT VÁ THÔNG LIÊN NHĨ Ở TRẺ DƯớI 10 KG TẠI TRUNG TÂM TIM MẠCH - BỆNH VIỆN E
}

Vũ Thị Chang ${ }^{1}$, Đinh Phuơng Thảo ${ }^{1}$, Nguyên Trần Thủy ${ }^{2 *}$, Đố Anh Tiến ${ }^{2 *}$

\section{TÓM TĂT}

Muc tiêu: Mô tả đặc điểm lâm sàng, cận lâm sàng và đánh giá kết quả sớm sau phẫu thuật đóng thông liên nhĩ đơn thuần ở trẻ em có cân nặng dưới $10 \mathrm{~kg}$ tại Trung tâm tim mạch - Bệnh viện E.

Đối tựng và phương pháp nghiên cúu: Nghiên cứu mô tả, hồi cứu. Từ tháng $1 / 2015$ đến tháng 7/2020, có 50 bệnh nhân (BN) dưới $10 \mathrm{~kg}$ được chẩn đoán thông liên nhĩ (TLN) đơn thuần được phẫu thuật (PT) với tuổi trung bình: 16,14 \pm 8,35 tháng ( 3 - 38 tháng), cân nặng trung bình: $7,8 \pm 1,73 \mathrm{~kg}(3,5-10 \mathrm{~kg})$.

Kết quả nghiên cứu: Tiền sử bệnh: chậm tăng cân $(78.0 \%)$, mệt khi gắng sức $(40.0 \%)$, viêm phổi tái diễn $(36.0 \%), 16.0 \%$ không biểu hiện triệu chứng và được phát hiện bệnh một cách tình cờ; $14 \% \mathrm{BN}$ kèm dị tật bẩm sinh khác ngoài tim, hội chứng Down thường gặp nhất $(8.0 \%)$. Trước PT: $56.0 \% \mathrm{BN}$ suy dinh dưỡng, chủ yếu là suy dinh dưỡng ở mức độ nhẹ (36.0\%); khám tim có tiếng thổi tâm thu là triệu chứng thường gặp nhất (94.0\%), T2 mạnh tách đôi (32.0\%); mức độ suy tim: $52 \%$ có suy tim, suy tim mức độ nhẹ $(46.0 \%)$. CLS trước PT: ĐTĐ thấy tăng gánh thất phải $(84.0 \%)$, trục phải $(68.0 \%)$ và block nhánh phải không hoàn toàn $(50.0 \%)$; Xquang ngực thẳng có tăng tuần hoàn phổi $(90.0 \%)$, bóng tim to $(48.0 \%)$, cung động mạch phổi (ĐMP) phồng (28.0\%); SAT: 100\% EF bình thường; 100\% TLN 1ỗ lớn (trung bình $15.8 \pm 3.72 \mathrm{~mm}$ ); 96.0\% TLN lỗ thứ phát; áp lực ĐMP tâm thu (ALĐMP) trung bình là $29.3 \pm 12.88 \mathrm{mmHg}, 38 \%$ tăng nhẹ và vừa, $4.0 \%$ tăng nặng; tỉ số đường kính thất phải/thất trái (ĐKTP/ĐKTT) tăng 98.0\% (trung bình: $0.84 \pm 0.21$ ), chủ yếu tăng nhẹ đến vừa (60.0\%). Sau đóng lỗ TLN, các triệu chứng LS và CLS được cải thiện gần như hoàn toàn so với trước PT $(\mathrm{p}<0.001)$. Biến chứng: $2 \mathrm{BN}$ còn shunt tồn lưu rất nhỏ, $2 \mathrm{BN}$ chảy máu sau mổ, không $\mathrm{BN}$ nào có rối loạn nhịp tim, tai biến mạch máu não và tử vong.

Kết luận: Mặc dù TLN được ghi nhận là bệnh TBS có tiến triển chậm, biến chứng thường xảy ra muộn, nhưng thực tế chúng tôi thấy bệnh có thể gây các biến chứng sớm như chậm tăng cân, viêm phổi tái diễn, SDD, suy tim, tăng ALĐMP sớm chiếm số lượng không ít và cần can thiệp $\mathrm{PT}$ sớm. PT đóng lỗ TLN ở trẻ dưới $10 \mathrm{~kg}$ là phương pháp an toàn và mang lại hiệu quả cao. Sau khi đóng lỗ TLN, đặc biệt, ở lứa tuổi nhỏ, giai đoạn bệnh sớm giúp giảm tỉ lệ và mức độ nặng của các biến chứng cũng như làm tăng hiệu quả cải thiện về LS và CLS cho trẻ sớm sau can thiệp.

Tù khóa: Thông liên nhĩ, trẻ em dưới 10kg, phẫu thuật vá thông liên nhĩ

SUMMARY

EVALUATION OF RESULTS AFTER SURGICAL CLOSURE OF ATRIAL SEPTAL DEFECTS IN CHILDREN WEIGHING LESS THAN 10KG AT THE CARDIOVASCULAR CENTRE - E HOSPITAL

\footnotetext{
${ }^{I}$ Truờng Đại học Y-Dượ, Đại học Thái Nguyên

${ }^{2}$ Trung tâm Tim mạch - Bệnh viện $E$

*Tác giả liên hệ: Nguyê̂n Trần Thủy \& Đố Anh Tiến; Email: drtranthuyvd@gmail.com \& bsdoanhtien@gmail.com
} 
Objectives: To describe the clinical and subclinical characteristics and evaluate the early results after simple atrial septal closure surgery in children weighing less than $10 \mathrm{~kg}$ at the Cardiovascular Centre - E Hospital.

Subjects and Methods: Retrospective descriptive study, from January 2015 to July 2020, we surgery closure of isolated ASD in children with procedural weight less than $10 \mathrm{~kg}$ for 50 patiens. Mean age $16.14 \pm 8.35$ months ( $3-38$ months), average age $7.8 \pm 1.73 \mathrm{~kg}(3.5-10 \mathrm{~kg})$

The patient was evaluated clinically and subclinically (electrocardiogram (ECG), chest Xray and echocardiography) upon admission to the hospital. At the time of hospital discharge, the child was evaluated for clinical, ECG and echocardiography return to assess the effectiveness of early post-closure of the ventricular fibrillation.

Results: History: slow weight gain (78.0\%), fatigue on exertion (40.0\%), recurrent pneumonia $(36.0 \%), 16.0 \%$ of patients had no symptoms and the disease was detected only once. By chance; $14 \%$ of patients had congenital malformations other than heart, Down syndrome was the most common (8.0\%). Preoperative clinical: $56.0 \%$ of patients are malnourished, mainly with mild malnutrition (36.0\%); cardiac examination with asystolic murmur was the most common symptom (94.0\%), strong T2 split (32.0\%); heart failure degree: $52 \%$ of patients had heart failure, mild heart failure 46.0\%. Subclinical: EGG shows increased right ventricular load (84.0\%), right axis $(68.0 \%)$ and incomplete right bundle branch block (50.0\%); straight chest X-ray showed increased pulmonary circulation $(90.0 \%)$, enlarged heart (48.0\%), enlarged pulmonary artery arch (28.0\%); Echocardiography: 100\% EF normal;
$100 \%$ large size vents (mean $15.8 \pm 3.72 \mathrm{~mm}$.); $96.0 \%$. Secondary atrial septal defect; mean asystolic pulmonary artery pressure was $29.3 \pm$ $12.88 \mathrm{mmHg}, 38 \%$ increased slightly and moderately, $4.0 \%$ increased seriously; TP/TT diameter ratio increased by $98.0 \%$ (Mean: $0.84 \pm$ $0.21)$, mainly slightly to moderate $(60.0 \%)$. After the closure of the atrial septal defect, the clinical and laboratory symptoms improved almost completely compared with before surgery $(p<$ 0.001). Complications: Two patients had the very small residual shunt. 2 patients had postoperative bleeding, no patient had arrhythmia, cerebrovascular accident and died.

Conclusion: Although atrial septal defect is recognized as a congenital heart disease with slow progression, complications often occur late, but in fact we found that the disease can cause early complications such as slow weight gain, recurrent pneumonia. Chronic disease, malnutrition, heart failure, early pulmonary hypertension account for a large number and require early surgical intervention. Surgery to close the atrial septal defect in children under 10 $\mathrm{kg}$ is a safe and highly effective method. After closure of the stoma, especially at a young age, the early disease stage helps to reduce the rate and severity of complications as well as increase the effectiveness of clinical and subclinical improvement for children soon after surgery card.

Key word: atrial septal defect, less than $10 \mathrm{~kg}$, surgical closure of atrial septal defects

\section{I. ĐẶT VẤN ĐỀ}

TLN là một bệnh TBS có khiếm khuyết ở vách liên nhĩ gây nên luồng thông từ trái sang phải. Bệnh thường gặp, chiếm tỉ lệ 10 - 15\% bệnh TBS, với tỷ lệ nữ/nam khoảng 2/1 [22]. TLN có thể đơn thuần hoặc kết hợp với các dị tật TBS 
khác. Các TLN kích thước nhỏ dưới $3 \mathrm{~mm}$ thường tự đóng. TLN lỗ lớn hoặc TLN ở trẻ lớn và người lớn không có khả năng tự đóng, cần điều trị triệt để bằng PT hoặc bít dù qua da.

Theo y văn, bệnh thường có triệu chứng LS kín đáo ở trẻ nhỏ do đó thường bị bỏ sót chẩn đoán cho đến tuổi trưởng thành. PT đóng TLN thường được trì hoãn đến 4 - 5 tuổi vì còn khả năng tự đóng và trẻ dung nạp tốt; cân nặng trên $15 \mathrm{~kg}$ có thể thuận lợi và đơn giản hơn [19]. Tuy nhiên, nếu không được điều trị, bệnh có thể gây nên nhiều biến chứng: chậm phát triển thể chất, viêm phổi tái diễn, suy tim và tăng ALĐMP... Nếu để muộn, có khả năng thất phải bị giãn tăng dần, suy giảm chức năng thất phải đồng thời suy giảm chức năng thất trái. Tại Trung tâm tim mạch - Bệnh viện $\mathrm{E}$, chúng tôi đã tiến hành PT vá TLN cho những trẻ có chỉ định $\mathrm{PT}$ và không chờ đợi cân nặng cũng như tuổi giúp hạn chế được các biến chứng cho $\mathrm{BN}$. Do đó, chúng tôi tiến hành $\mathrm{NC}$ với mục đích mô tả đặc điểm $\mathrm{LS}, \mathrm{CLS}$ và đánh giá kết quả sớm sau PT vá TLN đơn thuần ở trẻ em có cân nặng dưới $10 \mathrm{~kg}$ tại Trung tâm tim mạch - Bệnh viện E.

\section{II. ĐỐI TƯợNG VÀ PHƯƠNG PHÁP NC}

Nghiên cứu mô tả cắt ngang, hồi cứu. 50 $\mathrm{BN}$ dưới $10 \mathrm{~kg}$ được $\mathrm{PT}$ vá TLN đơn thuần từ tháng $1 / 2015$ đến tháng 7/2020 tại Trung tâm tim mạch - Bệnh viện E.

Chỉ định PT đóng TLN: BN có chỉ đóng TLN và không thực hiện được bằng bít dù.

- $\mathrm{BN}$ có triệu chứng SDD, suy tim, viêm phổi tái tái diễn không kiểm soát được bằng điều trị nội khoa.

Tăng ALĐMP, có bằng chứng tăng gánh thất phải: $\mathrm{Qp} / \mathrm{Qs} \geq 1.5$, ĐKTP/ĐKTT tăng, giãn buồng thất phải, tăng tưới máu phổi trên phim chụp Xquang ngực thẳng.

Thăm dò trước PT gồm khám LS, ĐTĐ, Xquang ngực thẳng và $\mathrm{SAT}$. Khi ra viện, $\mathrm{BN}$ được đánh giá lại về $\mathrm{LS}$, ĐTĐ và SAT.

Các kết quả được thống kê, phân tích, so sánh từ đó đưa ra nhận xét về đặc điểm LS, CLS và đánh giá kết quả sớm sau PT (phần mềm SPSS 25.0).

\section{KẾT QUẢ}

\section{1. Đặc điểm lâm sàng trước và sau phẫu thuật}

Bảng 1. Thời điểm phát hiện bệnh tim bẩm sinh và dị tật bẩm sinh kèm theo

\begin{tabular}{|l|l|c|c|}
\hline \multicolumn{2}{|l|}{ Triệu chứng } & $\mathrm{n}$ & $\%$ \\
\hline \multirow{4}{*}{ Tiền sử bệnh } & Chậm tăng cân & 39 & 78.0 \\
\cline { 2 - 4 } & Viêm phồi tái diễn & 18 & 36.0 \\
\cline { 2 - 4 } & Mệt khi gắng sức & 20 & 40.0 \\
\cline { 2 - 4 } & Không có triệu chứng & 8 & 16.0 \\
\hline \multirow{2}{*}{$\begin{array}{l}\text { Dị tật bẩm sinh ngoài } \\
\text { tim phối hợp }\end{array}$} & Hội chứng Down & 4 & 8.0 \\
\cline { 2 - 4 } & Dị tật khác & 3 & 6.0 \\
\cline { 2 - 4 } & Không có dị tật kèm theo & 43 & 86.0 \\
\hline
\end{tabular}


Bảng 2. Tình trạg phát triển thể chất truớc phẫu thuật

\begin{tabular}{|l|c|c|}
\hline Tình trạng SDD & $\mathbf{N}$ & $\mathbf{\%}$ \\
\hline SDD nhẹ & 18 & 36.0 \\
\hline SDD vừa & 5 & 10.0 \\
\hline SDD nặng & 5 & 10.0 \\
\hline Không SDD & 22 & 44.0 \\
\hline Tổng & 50 & 100 \\
\hline
\end{tabular}

Bảng 3. Triệu chứng thục thể trước phẫu thuật và khi ra viện

\begin{tabular}{|l|c|c|c|c|c|}
\hline \multirow{2}{*}{ Triệu chứng Thời điểm } & \multicolumn{2}{|c|}{ Trước phẫu thuật } & \multicolumn{2}{|c|}{ Khi ra viện } & \multirow{2}{*}{ p } \\
\cline { 2 - 5 } & $\mathrm{n}$ & $\%$ & $\mathrm{n}$ & $\%$ & \\
\hline Tiếng TTT & 47 & 94.0 & 0 & 0.0 & \multirow{2}{*}{$<0.001$} \\
\hline T2 mạnh, tách đôi & 16 & 32.0 & 0 & 0.0 & \\
\hline
\end{tabular}

Bảng 4. Mức độ suy tim của bệnh nhân trước phẫu thuật và khi ra viện

\begin{tabular}{|l|c|c|c|c|c|}
\hline \multirow{2}{*}{ Mức độ suy tim } & \multicolumn{2}{|c|}{ Trước phẫu thuật } & \multicolumn{2}{c|}{ Khi ra viện } & \multirow{2}{*}{ P } \\
\cline { 2 - 5 } & $\mathbf{n}$ & $\mathbf{\%}$ & $\mathbf{n}$ & $\mathbf{\%}$ & \\
\hline Mức độ nhẹ & 23 & 46.0 & 2 & 4.0 & $<0.001$ \\
\hline Mức độ trung bình & 3 & 6.0 & 0 & 0.0 & 0.25 \\
\hline Không suy tim & 24 & 48.0 & 48 & 96.0 & $<0.001$ \\
\hline Tổng & 50 & 100 & 50 & 100 & \\
\hline
\end{tabular}

3.2. Đặc điểm cận lâm sàng trước và sau phẫu thuật đóng lỗ thông liên nhĩ

Bảng 5. Đặc điểm điện tâm đồ trước phẫu thuật và khi ra viện

\begin{tabular}{|c|c|c|c|c|c|c|}
\hline \multirow{2}{*}{\multicolumn{2}{|c|}{ Đặc điểm }} & \multicolumn{2}{|c|}{ Trước phẫu thuật } & \multicolumn{2}{|c|}{ Khi ra viện } & \multirow{2}{*}{$\mathbf{P}$} \\
\hline & & $\mathbf{n}$ & $\%$ & $\mathbf{n}$ & $\%$ & \\
\hline \multicolumn{2}{|l|}{ Nhịp xoang } & 50 & 100 & 50 & 100 & \\
\hline \multicolumn{2}{|c|}{ Block nhĩ thất cấp I } & 1 & 2.0 & 0 & 0.0 & \\
\hline \multirow{3}{*}{$\begin{array}{l}\text { Block } \\
\text { nhánh phải }\end{array}$} & Hoàn toàn & 0 & 0.0 & 0 & 0.0 & \\
\hline & Không hoàn toàn & 25 & 50.0 & 2 & 4.0 & \multirow{5}{*}{$<0.001$} \\
\hline & Không & 25 & 50.0 & 48 & 96.0 & \\
\hline \multirow{2}{*}{$\begin{array}{l}\text { Trục điện } \\
\text { tim }\end{array}$} & Trục phải & 34 & 68.0 & 2 & 4.0 & \\
\hline & Trục trung gian & 16 & 32.0 & 48 & 96.0 & \\
\hline \multicolumn{2}{|c|}{ Tăng gánh TP } & 42 & 84.0 & 2 & 4.0 & \\
\hline
\end{tabular}


Bảng 6. Đặc điểm Xquang tim phổi truớc PT

\section{Dấu hiệu Xquang}

Tăng tuần hoàn phổi

Cung ĐMP phồng

Bóng tim to

\begin{tabular}{|c|c|}
\hline $\mathbf{n}$ & $\mathbf{\%}$ \\
\hline 45 & 90.0 \\
\hline 14 & 28.0 \\
\hline 24 & 48.0 \\
\hline
\end{tabular}

Bảng 7. Đặc điểm siêu âm tim trước phẫu thuật

\begin{tabular}{|l|l|c|c|}
\hline \multirow{2}{*}{ Đặc điểm siêu âm Doppler tim } & $\mathbf{n}$ & $\mathbf{\%}$ \\
\hline \multirow{2}{*}{ Loại lỗ TLN } & Lỗ thứ phát & 48 & 96.0 \\
\cline { 2 - 4 } & Lỗ tiên phát và xoang TMC dưới & 2 & 4.0 \\
\hline \multirow{2}{*}{$\begin{array}{l}\text { Kích thước lỗ } \\
\text { TLN }\end{array}$} & Lớn $(>8 \mathrm{~mm})$ & 50 & 100.0 \\
\cline { 2 - 4 } & Nhỏ và trung bình $(\leq 8 \mathrm{~mm})$ & 0 & 0.0 \\
\cline { 2 - 4 } & Giá trị trung bình $\pm \mathrm{SD}$ & \multicolumn{2}{|c|}{$15.8 \pm 3.72 \mathrm{~mm}$} \\
\hline \multirow{2}{*}{$\begin{array}{l}\text { ALĐMP tâm } \\
\text { thu (mmHg) }\end{array}$} & $<30 \mathrm{mmHg}$ & 29 & 58.0 \\
\cline { 2 - 4 } & $30-40 \mathrm{mmHg}$ & 8 & 16.0 \\
\cline { 2 - 4 } & $40-60 \mathrm{mmHg}$ & 11 & 22.0 \\
\cline { 2 - 4 } & $>60 \mathrm{mmHg}$ & 2 & 4.0 \\
\hline \multirow{2}{*}{$\begin{array}{l}\text { Tí số } \\
\text { ĐKTP/ĐKTT }\end{array}$} & $<1 / 2$ & 5 & 2.0 \\
\cline { 2 - 4 } & $1 / 2 \leq-<2 / 3$ & 19 & 30.0 \\
\cline { 2 - 4 } & $2 / 3 \leq-<1$ & 50 & 100.0 \\
\cline { 2 - 4 } & $\geq 1$ & 0 & 0.0 \\
\hline
\end{tabular}

Bảng 8. Sự thay đổi các thông số siêu âm tim trước phẫu thuật và khi ra viện

\begin{tabular}{|l|c|c|c|}
\hline \multirow{2}{*}{ Các Thời điểm } & Trước phẫu thuật & Khi ra viện & \multirow{2}{*}{ P } \\
\cline { 2 - 3 } & \multicolumn{2}{|c|}{ Giá trị trung bình \pm SD } & \\
\hline Đường kính TP $(\mathrm{mm})$ & $17.06 \pm 3.64$ & $11.12 \pm 1.8$ & \\
\cline { 2 - 3 } Đường kính TT $(\mathrm{mm})$ & $20.76 \pm 2.99$ & $23.2 \pm 3.02$ & \multirow{2}{*}{0.001} \\
\cline { 1 - 3 } Tỉ số ĐKTP/ĐKTT & $0.84 \pm 0.21$ & $0.49 \pm 0.01$ & \\
\hline ALĐMP tâm thu $(\mathrm{mmHg})$ & $29.3 \pm 12.88$ & $16.62 \pm 5.71$ & \\
\hline EF (\%) & $70.74 \pm 7.05$ & $74.6 \pm 7.17$ & \\
\hline
\end{tabular}


Bảng 9. Các biến chứng sau phẫu thuật

\begin{tabular}{|l|c|c|}
\hline Biến chứng & $\mathbf{N}$ & $\mathbf{\%}$ \\
\hline Shunt tồn lưu & 2 & 4.0 \\
\hline Rối loạn nhịp tim & 0 & 0 \\
\hline Tai biến mạch máu não & 0 & 0 \\
\hline Chảy máu sau mổ & 2 & 4.0 \\
\hline Tử vong & 0 & 0 \\
\hline
\end{tabular}

\section{BÀN LUẬN}

\section{1. Đặc điểm chung}

Trong NC của chúng tôi, độ tuổi trung bình là $16.14 \pm 8.35$ tháng (nhỏ nhất là 3 tháng và lớn nhất là 38 tháng); cân nặng trung bình là $7.8 \pm 1.73 \mathrm{~kg}$ (lớn nhất là $10 \mathrm{~kg}$ và nhỏ nhất là $3.5 \mathrm{~kg}$ ). Theo y văn, TLN thường có triệu chứng kín đáo ở lứa tuổi còn nhỏ. PT đóng lỗ TLN thường được trì hoãn đến khoảng $4-5$ tuổi và cân nặng trên $15 \mathrm{~kg}$ có nhiều thuận lợi hơn [19]. Tuy nhiên, trong thực tế NC của chúng tôi và một số tác giả khác cho thấy tỉ lệ trẻ nhỏ có TLN phải nhập viện điều trị khá cao: Trương Bích Thủy (tuổi nhập viện trung bình là $26.29 \pm$ 25.17 tháng, trong đó có $80.7 \%$ ở tuổi dưới 36 tháng) [9], Pankaj G (độ tuổi và cân nặng trung bình lần lượt là $17.97 \pm 8.63$ tháng và $8.06 \pm$ $1.59 \mathrm{~kg}$ trong đó $83 \%$ trẻ có cân nặng dưới 10 kg) [15], Tanghöj G (cân nặng trung bình là $11.3 \mathrm{~kg}$ ) [16]. Lứa tuổi và cân nặng của $\mathrm{BN}$ trong $\mathrm{NC}$ của chúng tôi thấp hơn so với một số NC khác trước đây: Trương Thanh Hương (tuổi và cân nặng trung bình là $9.19 \pm 4.58$ tuổi và $26.06 \pm 13.48 \mathrm{~kg}$ ) [4], Lê Mỹ Hạnh (tuổi trung bình là $13.2 \pm 24$ tuổi) [2]; tác giả Butera (độ tuổi trung bình là $3.6 \pm 1.3$ tuổi) [12]. Điều này cho thấy có sự tiến bộ trong lĩnh vực PT TBS trong những năm gần đây tại Trung tâm Tim mạch - Bệnh viện $E$ nói riêng và chuyên ngành PT tim mạch Việt Nam nói chung có thể tiến hành $\mathrm{PT}$ sửa chữa $\mathrm{TBS}$ khi có chỉ định mà không cần chờ đợi độ tuổi và cân nặng của $\mathrm{BN}$, giúp hạn chế các biến chứng cho trẻ.

\section{2. Đặc điểm lâm sàng trước phẫu thuật Tiền sử bệnh}

Khai thác tiền sử thấy rằng chậm tăng cân là triệu chứng thường gặp nhất (78.0\%), sau đó là mệt khi gắng sức $(40.0 \%)$ và tình trạng viêm phổi tái diễn (36.0\%), chỉ $16.0 \%$ trẻ không có biểu hiện triệu chứng và được phát hiện bệnh một cách tình cờ. Kết quả của này tương tự $\mathrm{NC}$ : Trương Thanh Hương thấy $(74.2 \% \mathrm{BN}$ chậm lớn, chỉ $22.6 \%$ trẻ không có triệu chứng và được phát hiện tình cờ) [4], Michael (50\% số BN có tình trạng chậm phát triển về thể chất, nhiễm trùng hô hấp thường xuyên 41,67\%) [18]. Như vậy, các triệu chứng trong tiền sử của BN TLN thường gặp là tình trạng chậm phát triển về thể chất, mệt khi gắng sức và viêm phổi tái diễn. Đây là những triệu chứng không đặc hiệu, có thể gặp trong nhiều bệnh lý khác nhau. Vì vậy, gợi ý này giúp các bác sĩ LS có những lưu ý trong chẩn đoán, sàng lọc và phát hiện bệnh sớm. 


\section{Dị tật bẩm sinh kèm theo}

$14 \%$ trẻ có kèm dị tật bẩm sinh khác ngoài tim, trong đó hội chứng Down thường gặp nhất $(8.0 \%)$. Y văn và nhiều nghiên cứu khác cũng kết luận Down là dị tật bẩm sinh thường kết hợp nhất với TBS [13], [21].

Tình trạng phát triển thể chất trước phẫu thuật

$56.0 \%$ trẻ có tình trạng SDD trước PT với chủ yếu là SDD ở mức độ nhẹ $(36.0 \%)$. Kết quả này tương tự với tác giả Trương Bích Thủy: $42.9 \%$ trẻ có tình trạng SDD, trong đó chủ yếu SDD mức độ nhẹ $(28 \%)$, SDD vừa và nặng lần lượt là $9.3 \%$ và $5.6 \%$ [9].

\section{Triệu chúng khám tim}

Các triệu chứng thường thấy là dấu hiệu gián tiếp của việc tăng cung lượng máu lên phổi và ALĐMP: tiếng TTT, tiếng T2 mạnh, tách đôi. Trong NC của chúng tôi, triệu chứng nghe có tiếng TTT là triệu chứng thường gặp nhất chiếm $94.0 \%$. Kết quả này cũng tương tự với một số NC: Nguyễn Hoàng Nam (100\% có TTT) [5], Nguyễn Lân Hiếu (85\% có TTT) [3].

\section{Múc độ suy tim trước PT}

$52 \%$ số BN có tình trạng suy tim, trong đó chủ yếu suy tim giai đoạn sớm $(46.0 \%$ trẻ suy tim mức độ nhẹ), không có trẻ nào suy tim mức độ nặng. So sánh với NC của tác giả Nguyễn Hoàng Nam có kết quả tương tự trong nhóm trẻ em, suy tim chủ yếu ở giai đoạn nhẹ đến trung bình (suy tim nhẹ là $69.2 \%$ ), không có trẻ nào suy tim mức độ nặng. Khi so sánh với nhóm người lớn chủ yếu suy tim mức độ trung bình và nặng $(66.7 \%$ và 7.7\%) [5]. So sánh mức độ suy tim trong NC của chúng tôi với một số $\mathrm{NC}$ ở $\mathrm{BN}$ người lớn khác cũng cho thấy mức độ suy tim ở lứa tuổi nhỏ thấp hơn so với nhóm $\mathrm{BN}$ lớn tuổi: Trần Thanh Thái Nhân (tuổi NC trung bình 36.19 13.19 tuổi, suy tim mức độ vừa và nặng lần lượt là $61.3 \%$ và $35.5 \%$ ) [7]. Điều này phù hợp do sinh lý bệnh một cách âm thầm của bệnh. Trẻ phát hiện bệnh ở giai đoạn sớm nên mức độ suy tim còn nhẹ. Ở người lớn do bệnh tiến triển lâu năm và khi phát hiện bệnh hầu hết đã có biểu hiện các biến chứng của bệnh.

\section{3. Đặc điểm cận lâm sàng trước phẫu} thuật

\section{Điện tâm đồ}

Dấu hiệu tăng gánh TP, rối loạn dẫn truyền (thường gặp block nhánh phải không hoàn toàn), trục tim lệch phải, muộn hơn nữa là các rối loạn nhịp nhĩ... là những biểu hiện thường gặp trong bệnh TLN [19].

Trong NC của chúng tôi $100 \%$ BN có nhịp xoang, các dấu hiệu thường gặp trên ĐTĐ là tăng gánh TP $(84.0 \%)$, trục phải $(68.0 \%)$ và block nhánh phải không hoàn toàn $(50.0 \%)$. Các dấu hiệu này cũng tương tự như các tác giả khác: Nguyễn Minh Trí Việt (77.3\% tăng gánh TP) [11]. Kết quả này có thấp hơn $\mathrm{NC}$ của Nguyễn Thị Mai Ngọc trên $\mathrm{BN}$ người lớn: trục phải $90.2 \%$, block nhánh phải không hoàn toàn $93.5 \%$, phì đại thất phải $83.7 \%$ [6].

\section{Xquang ngục thẳng}

Những dấu hiệu thường gặp trên Xquang ngực thẳng là các dấu hiệu đặc trưng của các bệnh lý có luồng thông trái - phải gây tăng lưu lượng máu $\mathrm{TP}$ và tuần hoàn phổi gây ra. Trong $\mathrm{NC}$ này, thường thấy nhất là tăng tuần hoàn phổi chủ động 45/50 trẻ $(90.0 \%)$, sau đó là bóng tim to 
gặp 48.0\%, cung ĐMP phồng gặp 28.0\% số BN. Kết quả này cũng tương tự với Trương Bích Thủy, Nguyễn Minh Trí Việt [9], [11].

\section{Siêu âm Doppler tim}

SAT cho thấy $100 \% \mathrm{BN}$ có chức năng tim bình thường, $100 \% \mathrm{BN}$ có TLN lỗ lớn (kích thước lố thông trung bình là $15.8 \pm 3.72 \mathrm{~mm}$ ). $96.0 \%$ là TLN lỗ thứ phát. Đây cũng là loại lỗ thông thường gặp nhất trong bệnh TLN được ghi nhận trong y văn [22].

$42.0 \%$ trẻ trong NC này có tình trạng tăng ALĐMP tâm thu, trong đó chủ yếu tăng mức độ nhẹ và vừa $(38 \%)$, tăng nặng chỉ $4.0 \%$ số $\mathrm{BN}$. Kết qủa này thấp hơn của Trương Bích Thủy, Nguyễn Hoàng Nam [5], [9]. Điều này hoàn toàn hợp lý bởi độ tuổi $\mathrm{NC}$ của các tác giả trên cao hơn trong $\mathrm{NC}$ của chúng tôi. Các $\mathrm{BN}$ lứa tuổi thấp, bệnh chưa tiến triển lâu ngày, được điều trị ở giai đoạn sớm nên ALĐMP còn chưa tăng nhiều.

Hầu hết trẻ trong nhóm $\mathrm{NC}$ có tình trạng tăng gánh TP trên SAT với tỉ số ĐKTP/ĐKTT $\geq$ $1 / 2(98.0 \%)$, với tỉ lệ tăng mức độ nhẹ đến vừa chiếm đa số $(60.0 \%)$. Kết quả này phù hợp với tình trạng tăng ALĐMP.

\subsection{Kết quả sớm sau phẫu thuật}

\section{Lâm sàng}

Sau đóng luồng thông trái - phải, 100\% $\mathrm{BN}$ không còn TTT và T2 mạnh, tách đôi khi thăm khám.

Mức độ suy tim lúc ra viện được cải thiện rõ rệt so với trước PT: $96.0 \%$ trẻ không còn tình trạng suy tim lúc ra viện, không có trẻ nào suy tim mức độ trung bình và chỉ $4.0 \%$ trẻ suy tim mức độ nhẹ $(\mathrm{p}<0.001)$. $\mathrm{BN}$ được $\mathrm{PT}$ ở giai đoạn bệnh sớm, mức độ suy tim nhẹ sẽ cho kết quả cải thiện tốt hơn so với PT bệnh ở giai đoạn muộn, mức độ suy tim nặng hơn [5].

\section{Cận lâm sàng \\ $\boldsymbol{\oplus T \boldsymbol { \theta }}$}

Các dấu hiệu trên ĐTĐ được giảm đi rõ rệt sau khi đóng luồng thông trái - phải. Tỉ lệ block nhánh phải không hoàn toàn là $50 \%$, điện tim trục phải $68.0 \%$ và tăng gánh thất phải $84.0 \%$ giảm xuống lần lượt là $4.0 \%, 4.0 \%$ và $4.0 \%$ khi ra viện $(\mathrm{p}<0.001)$. Kết quả này cũng tốt hơn $\mathrm{NC}$ của Nguyễn Hoàng Nam trong nhóm BN lớn tuổi [5].

\section{SA Doppler tim}

- Sự cải thiện về mặt huyết động: ALĐMP tâm thu khi ra viện giảm so với trước PT (16.62 \pm $5.71 \mathrm{mmHg}$ so với trước PT là $29.3 \pm 12.88$ $\mathrm{mmHg}$ ), không còn trẻ nào tăng ALĐMP mức độ vừa và nặng, 94.0\% trẻ có ALĐMP về bình thường, còn 3 trẻ $(6.0 \%)$ tăng ALĐMP tâm thu mức độ nhẹ. Sự cải thiện ALĐMP sớm ngay sau khi đóng lỗ TLN có kết luận chung trong nhiều nghiên cứu: tác giả Trương Quang Bình [1], Trương Tú Trạch [10]. Như vậy, sau khi đóng lỗ TLN, ALĐMP giảm rõ rệt. Sự cải thiện ALĐMP này giải thích là do giảm lưu lượng máu lên phổi qua lỗ thông trái - phải và mạch máu phổi còn khả năng phục hồi sau PT.

- Sự cải thiện về mặt giải phẫu: Có sự giảm đáng kể kích thước tâm thất phải và sự gia tăng kích thước tâm TT sau đóng lỗ TLN. Kết quả trong $\mathrm{NC}$ của chúng tôi cho thấy sau PT tâm thất phải nhỏ đi đáng kể $(11.12 \pm 1.8 \mathrm{~mm}$ so với $17.06 \pm 3.64 \mathrm{~mm}$ ) và kích thước TT tăng nhiều $(23.2 \pm 3.02 \mathrm{~mm}$ so với $20.76 \pm 2.99 \mathrm{~mm})$. Kết quả này phù hợp với kết quả của một số $\mathrm{NC}$ khác [14], [17]. Tái cấu trúc các buồng tim xảy ra sớm sau vá lỗ TLN, nhất là buồng thất phải, giải thích hiện tượng này là do sau đó luồng thông biến mất hoặc giảm đáng kể do đó giảm quá tải thể tích thất phải. 
Sự cải thiện về mặt LS và cận LS sau đóng lỗ TLN có mối tương quan với thời gian diễn tiến của bệnh trước PT. Bệnh được phát hiện và điều trị đóng lỗ TLN ở giai đoạn sớm khi có chỉ định, với tình trạng tăng gánh các buồng tim và tăng ALĐMP ở giai đoạn sớm là điều kiện thuận lợi cho sự cải thiện các triệu chứng sau đóng lỗ thông. Tác giả Pascotto và cộng sự NC về tái cấu trúc cơ tim sau đóng lỗ TLN thấy rằng có mối liên quan chặt chẽ giữa quá tải trước khi đóng luồng thông và sự giảm tải của nó từ khi luồng thông biến mất, tỉ lệ ĐKTP/ĐKTT càng lớn bao nhiêu thì khả năng tái cấu trúc thất phải càng nhiều bấy nhiêu sau đóng lố thông [20].

\section{Biến chúng}

Khi ra viện, có $2 \mathrm{BN}$ còn shunt tồn lưu rất nhỏ và không cần can thiệp gì; $2 \mathrm{BN}$ bị chảy máu sau mổ trong đó: $1 \mathrm{BN}$ phải mổ lại để cầm máu, 1 BN ổn định sau truyền các yếu tố đông máu; không có rối loạn nhịp, không có tai biến mạch máu não hoặc tử vong trong và sau mổ. Kết quả này cũng tương tự với Lê Mỹ Hạnh, Lê Quang Thứu, Gustaf [2], [8], [16]. Các biến chứng gặp phải trong PT vá TLN cũng tương tự như các PT tim khác. PT vá TLN có tỉ lệ biến chứng thấp. Hiện nay, nhờ sự phát triển của gây mê hồi sức, trình độ của $K T V$ và trang thiết bị hiện đại, việc hạ thấp độ tuổi và cân nặng PT là an toàn và có hiệu quả cao.

\section{KẾT LUẬA}

Mặc dù TLN được ghi nhận là bệnh lý có triệu chứng LS kín đáo ở trẻ nhỏ, rất hiếm khi suy tim trong năm đầu tiên do đó thường bị bỏ sót chẩn đoán cho đến tuổi trưởng thành. Tuy nhiên, số trẻ nhỏ TLN có biểu hiện các triệu chứng từ rất sớm: mệt khi gắng sức, viêm phổi tái diễn, chậm phát triển về thể chất, suy dinh dưỡng, suy tim, tăng ALĐMP... chiếm số lượng không ít và cần can thiệp PT sớm.

Sau khi đóng lỗ TLN, các triệu chứng LS, CLS được cải thiện rõ rệt. Đặc biệt, việc điều trị đóng lỗ TLN ở lứa tuổi nhỏ, giai đoạn bệnh sớm khi có chỉ định giúp giảm tỉ lệ và mức độ nặng của các biến chứng cũng như làm tăng hiệu quả cải thiện về LS và cận LS cho trẻ sớm sau can thiệp.

PT đóng lỗ TLN ở trẻ dưới $10 \mathrm{~kg}$ là phương pháp an toàn và mang lại hiệu quả cao.

\section{TÀI LIẸU THAM KHẢO:}

1. Trương Quang Bình, Đỗ Nguyên Tín và Võ Mỹ Phượng (2015), "Nghiên cứu hiệu quả của phương pháp đóng thông liên nhĩ lỗ thứ phát bằng dụng cụ qua thông tim can thiệp", Tạp chi Tim mạch học Việt Nam, 70, tr. 15-22.

2. Lê Mỹ Hạnh, Đặng Thị Hải Vân Đào Thúy Quỳnh và cộng sự (2016), "Nghiên cứu rối loạn nhịp tim sau phẫu thuật tim mở tại Bệnh viện Nhi Trung ương", Tạp chí nhi khoa, 9, tr. 48-53.

3. Nguyễn Lân Hiếu (2008), Nghiên cưu áp dụng phưong pháp bit lồ thông liên nhĩ qua da bằng dụng cu Amplatzer, Luận án Tiến sỹ Y học, Đại học Y Hà Nội.

4. Trương Thanh Hương (2008), "Vai trò của siêu âm Doppler tim trong theo dõi kết quả điều trị đóng lỗ thông liên nhĩ ở trẻ em", Tạp chí nghiên cúu y hoc, 56, tr. 23-26.

5. Nguyễn Hoàng Nam (2015), Đánh giá kết quả vá thông liên nhĩ theo phuoong pháp it xâm lấn với nội soi hỗ trợ, Luận văn Thạc sỹ Y học, Trường Đại học Y Hà Nội.

6. Nguyễn Thị Mai Ngọc (2011), Đánh giá súc cản động mạch phổi bằng siêu âm Doppler tim trước và sau điều trị đóng lỗ thông liên nhĩ, Luận án tiến sĩ y học, Trường Đại học y Hà Nội. 
7. Trần Thanh Thái Nhân (2018), "Đánh giá kết quả phẫu thuật đóng lỗ thông liên nhĩ bằng phương pháp ít xâm lấn với nội soi hỗ trợ không liệt tim tại Trung tâm tim mạch-Bệnh viện Trung ương Huế".

8. Lê Quang Thứu (2003), "Đánh giá sự thay đổi áp lực động mạch phổi sau phẫu thuật đóng thông liên nhĩ", Tạp chí khoa học Đại học Huế, 15, tr. 61-67.

9. Trương Bích Thủy và Vũ Minh Phúc (2009), "Đặc điểm thông liên nhĩ đơn thuần ở trẻ em tại Bệnh viện Nhi Đồng 1-TP. Hồ Chí Minh", Tạp chi Y Học TP. Hồ Chí Minh, 13, tr. 101-105.

10. Trương Tú Trạch và Võ Thành Nhân (2012), "Thủ thuật bít lỗ thông liên nhĩ bằng dụng cụ Amplatzer", Nghiên cúu Y hoc-Y hoc TP. Hồ Chí Minh, 16, tr. 98-103.

11. Nguyễn Minh Trí Việt và Võ Phan Thảo Trang Nguyễn Thị Thanh Lan (2012), "Đặc điểm dịch tê̂, lâm sàng, cận lâm sàng các trường hợp thông liên nhĩ lỗ thứ phát được chỉ định đóng bằng dụng cụ", Tạp chí Y Hoc TP. Hồ Chí Minh, 16, tr. 23-27.

12. Butera G., De Rosa Gabriell. Rosti L., et al (2003), "Transcatheter closure of atrial septal defect in young children: results and follow-up", Journal of the American College of Cardiology. 42(2), pp. 241-245.

13. Başpinar O., Karaaslan S. Oran B., et al (2006), "Prevalence and distribution of children with congenital heart diseases in the central Anatolian region, Turkey", Turk J Pediatr. 48(3), pp. 237-43.

14. Du Z. D., Cao Q. L. Koenig P., et all (2001), "Speed of normalization of right ventricular volume overload after transcatheter closure of atrial septal defect in children and adults",
American Journal of Cardiology. 88(12), pp. 1450-1453.

15. Garg P., et all (2017), "Cervical cannulation for surgical repair of congenital cardiac defects in infants and small children", Brazilian journal of cardiovascular surgery. 32, pp. 111-117.

16. Gustaf T., Michal O. Estelle N., et al (2017), "Early complications after percutaneous closure of atrial septal defect in infants with procedural weight less than $15 \mathrm{~kg}^{\prime \prime}$, Pediatric cardiology. 38(2), pp. 255-263.

17. Kucinska B., Werner B. and Maria W. (2010), "Assessment of right atrial and right ventricular size in children after percutaneous closure of secundum atrial septal defect with Amplatzer septal occluder", Archives of medical science: AMS. 6(4), pp. 567.

18. Michael V., Felix B. Ingo D., et al (2000), "Treatment of atrial septal defects in symptomatic children aged less than 2 years of age using the Amplatzer septal occluder", Cardiology in the Young. 10(5), pp. 534-537.

19. Park K. M. (2015), "Atrial Septal Defect", Pediatric Cardiology for Practitioners, pp. 278-285.

20. Pascotto M., Santoro G. Cerrato F., et all (2006), "Time-course of cardiac remodeling following transcatheter closure of atrial septal defect", International journal of cardiology. 112(3), pp. 348-352.

21. Vick G. W. and Louis I. B. (2020), "Isolated atrial septal defects in children: Management and outcome", http://www.uptodate.com.

22. Vick G. W. and Bezold L. I. (2018), "Isolated atrial septal defects (ASDs) in children: Classification, clinical features, and diagnosis", http://www.uptodate.com. 